\title{
Dependence of Thermal Responses of Composite Slabs Subjected to Fire on Cross Sectional Shapes
}

\author{
KAZUNORI HARADA and TOSHIO TERAI \\ Department of Architecture, Kyoto University, \\ Sakyo-ku, Yoshida-Hon-Machi, Kyoto, 606-01, Japan
}

\section{ABSTRACT}

Fire resistance of composite slab of steel deck and concrete is numerically examined. The model takes into account of the heat and mass transfer, the desorption of physically adsorbed water, and the thermal decomposition of water of crystallization. The accuracy of the model is verified by comparing with the fire test data. By using the model, the dependence of the thermal responses on the cross sectional shapes is derived. While the average thickness is kept constant $(115 \mathrm{~mm})$, the rib sizes are changed. The fire resistance time is determined for each shape. In case of small ribs, the fire resistance time is determined by the average temperature rise of the unexposed surface. On the contrary, as the rib becomes large, the fire resistance time is determined by the maximum temperature rise. Between these rib sizes, the two criteria are exceeded at the same time. We call these shapes as 'thermally optimum' in the sense that there is no redundancy of concrete. By extrapolating the results for $115 \mathrm{~mm}$ average thickness, thermally optimum shapes for different average thickness can be guessed.

KEY WORDS: Fire Resistance, Heat and Mass Transfer, Composite Slab, Thermally Optimum Shapes

\section{NOTATIONS}

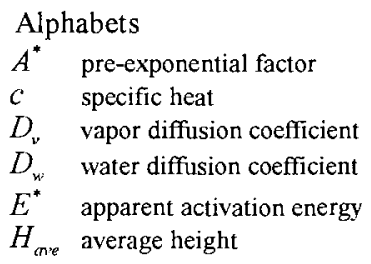

$\begin{array}{ll}\text { unit } & \text { eq. } \\ {[1 / \mathrm{s}]} & (7) \\ {[\mathrm{J} / \mathrm{kg} \cdot \mathrm{K}]} & (1) \\ {\left[\mathrm{m}^{2} / \mathrm{s}\right]} & (3) \\ {\left[\mathrm{nt}^{2} / \mathrm{s}\right]} & (4) \\ {[\mathrm{J} / \mathrm{kmol}]} & (7) \\ {[\mathrm{mm}]} & -\end{array}$

$H_{\text {min }}$ minimum height

$H_{r}$ rib height

[mm] -

$L_{s} \quad$ latent heat of desorption

[mm]

$[\mathrm{J} / \mathrm{kg}] \quad(1)$

$L_{d} \quad$ latent heat of decomposition $\quad[\mathrm{J} / \mathrm{kg}] \quad$ (1)

$R_{\text {sory }}$ rate of desorption

$R_{d c m p}$ rate of decomposition

$\left[\mathrm{kg} / \mathrm{m}^{3} \cdot \mathrm{s}\right](1)$

$\left[\mathrm{kg} / \mathrm{m}^{3} \cdot \mathrm{s}\right](1)$ 


\begin{tabular}{|c|c|c|c|c|c|c|c|}
\hline$t$ & time & [s] & (1) & $w$ & content of physically & & \\
\hline$t_{\text {ave }}$ & time to rise $140^{\circ} \mathrm{C}$ in average & {$[\mathrm{min}]$.} & (11) & & adsorbed water & {$[\mathrm{kg} / \mathrm{kg}]$} & (4) \\
\hline$t_{f r}$ & fire resistance time & {$[\min ]$.} & (11) & $w_{e q}$ & equilibrium water content & {$[\mathrm{kg} / \mathrm{kg}]$} & (6) \\
\hline$t_{\max }$ & time to rise $180^{\circ} \mathrm{C}$ in maximun & {$[\min ]$.} & (12) & $w_{c}$ & $\begin{array}{l}\text { content of water of } \\
\text { crystallization }\end{array}$ & {$[\mathrm{kg} / \mathrm{kg}]$} & (5) \\
\hline $\mathbf{u}$ & apparent velocity of gas & {$[\mathrm{m} / \mathrm{s}]$} & (2) & $W_{r}$ & rib width & {$[\mathrm{mm}]$} & - \\
\hline Gre & k Letters & unit & eq. & & & & \\
\hline$\gamma$ & rate constant of desorption & {$\left[\mathrm{kg} / \mathrm{m}^{3} \cdot \mathrm{s}\right]$} & $(6)$ & $\rho_{g}$ & density of mixed gas & {$\left[\mathrm{kg} / \mathrm{m}^{3}\right]$} & (2) \\
\hline$\varepsilon$ & void fraction & {$\left[\mathrm{m}^{3} / \mathrm{m}^{3}\right]$} & (2) & $\rho_{v}$ & density of water vapor & {$\left[\mathrm{kg} / \mathrm{m}^{3}\right]$} & (3) \\
\hline$\theta$ & $\begin{array}{l}\text { temperature } \\
\text { dry density of concrete }\end{array}$ & $\begin{array}{l}{\left[{ }^{\circ} \mathrm{C}\right]} \\
{\left[\mathrm{kg} / \mathrm{m}^{3}\right]}\end{array}$ & $\begin{array}{l}\text { (1) } \\
\text { (1) }\end{array}$ & $\lambda$ & thermal conductivity & {$[\mathrm{W} / \mathrm{m} \cdot \mathrm{K}]$} & (1) \\
\hline$\rho$ & dry density of concrete & {$\left[\mathrm{kg} / \mathrm{m}^{\top}\right]$} & (1) & $\kappa_{D}$ & permeability & {$\left[\mathrm{m}^{2} / \mathrm{Pa} \cdot \mathrm{s}\right]$} & ] (8) \\
\hline
\end{tabular}

\section{INTRODUCTION}

Concrete members are intensely heated during fire. When the temperature of the concrete reaches $100^{\circ} \mathrm{C}$, the temperature rises very slowly because the desorption of water takes place. This phenomenon is called 'creeping of temperature'. There are several models to predict the creeping of temperature of concrete members. Simple models are proposed by Kawagoel), Wakamatsu ${ }^{2)}$ and other authors. More sophisticated models include the desorption of physically adsorbed water, and subsequent vapor transfer in the pore. Harmathy ${ }^{3)}$ proposed a model of simultaneous heat and mass transfer, and predicted the drying process of porous brick. Similar models are proposed by Huang et $\mathrm{al}^{4)}$, Sahota et $\mathrm{al}^{5)}$ and other authors. Their models do not explicitly include the thermal decomposition of water of crystallization.

A model of heat and moisture transfer which takes into account the desorption of physically adsorbed water, the thermal decomposition of water of crystallization, and subsequent vapor transfer in the pore, is presented by the authors at the third symposium ${ }^{6}$ ). As the concrete is a mixture of fine and coarse aggregate, cement paste and air void, the transport parameters in the models are estimated by the mix proportions and the values of its components 7 ). Using the estimated transport parameters in the model, the variations of fire resistance time of flat walls are quantitatively derived ${ }^{8}$.

In this paper, the model is applied to the two dimensional heat and mass transfer process in composite slabs. The relationships between the cross sectional shapes and the fire resistance time are derived. For a fixed concrete volume, the rib width and height are varied in a possible range, and the variations of the fire resistance time is calculated for sandstone concrete. As to the concrete properties, calculations are carried out in case of chart and lightweight concrete, and the results are compared with that of sandstone concrete. The dependence on concrete volume is also stated.

\section{A MODEL OF HEAT AND MASS TRANSFER6)}

In order to simulate the heat and mass transfer process, concrete is treated as a porous material as shown in figure 1. The following five conservation equations of heat, gaseous mixture, water vapor, physically adsorbed water and the water of crystallization, 
$\rho c \frac{\partial \theta}{\partial t}=\nabla(\lambda \nabla \theta)-\left(L_{s} R_{s o r p}+L_{d} R_{d c m p}\right)$,

$\frac{\partial\left(\varepsilon \rho_{g}\right)}{\partial t}+\nabla\left(\rho_{g} \mathbf{u}\right)=R_{s o r p}+R_{d c m p}$,

$\frac{\partial\left(\varepsilon \rho_{v}\right)}{\partial t}+\nabla\left(\rho_{v} \mathbf{u}\right)=\nabla\left(D_{v} \nabla \rho_{v}\right)+R_{\text {sorp }}+R_{d c m p}$,

$\rho_{0} \frac{\partial w}{\partial t}=\nabla\left(\rho_{i} D_{w} \nabla w\right)-R_{\text {sorp }}$

$\rho_{0} \frac{\partial w_{c}}{\partial t}=-R_{d c m p}$

are applied. These equations are solved with the rate equations of desorption and decomposition,

$R_{\text {sorp }}=\gamma\left(w-w_{e q}\right)$,

$R_{d c n: p}=\rho_{0} \sum_{k=1}^{3} w_{c, k} A_{d l, k} \exp \left(-E_{d, k} / R T\right)$,

Darcy's law for gas filtration,

$\mathbf{u}=-\kappa_{D} \nabla P_{g}$,

and the equations of states,

$\rho_{g}=\left\{P_{v} M_{v}+\left(P_{g}-P_{v}\right) M_{a}\right\} / R T, \rho_{v}=P_{v} M_{v} / R T$.

The governing equations are nonlinear and so-called stiff. In order to overcome numerical instability, they are transformed into integral equations and integrated with respect to time by strongly stable implicit Runge-Kutta scheme ${ }^{9)}$.

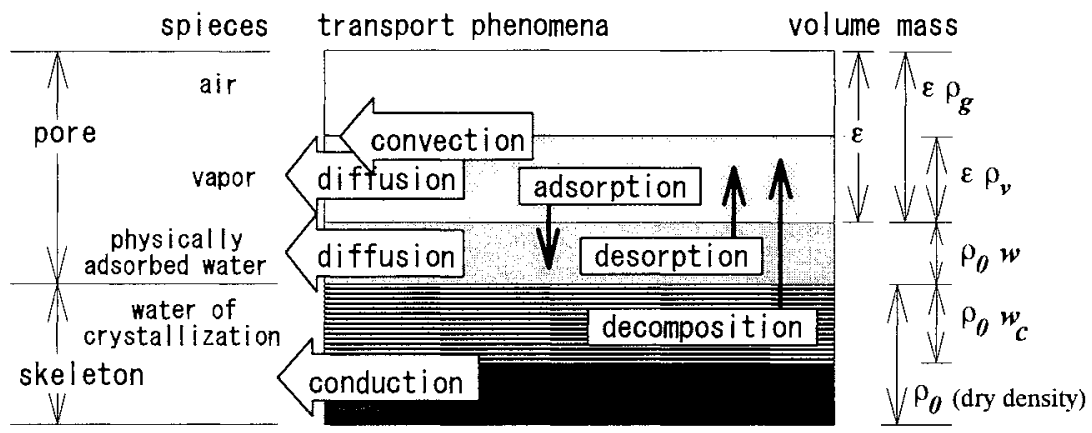

FIGURE 1 A model of heat and mass transfer 


\section{TRANSPORT PARAMETERS}

The transport parameters, such as thermal conductivity, specific heat, permeability and diffusion coefficients, void fraction, are strongly dependent on the mix design of concrete The thermal conductivity of concrete of any arbitrates mix proportions are estimated by applying the Maxwell's relation to the measured thermal conductivity of fine and coarse aggregate, cement paste ${ }^{7,8}$. The other transport parameters can be also estimated from its mix design.

Transport parameters of typical sandstone(S), chart(C) and lightweight concrete(L) are estimated, and shown in figure 2. These parameters are used in the following calculations
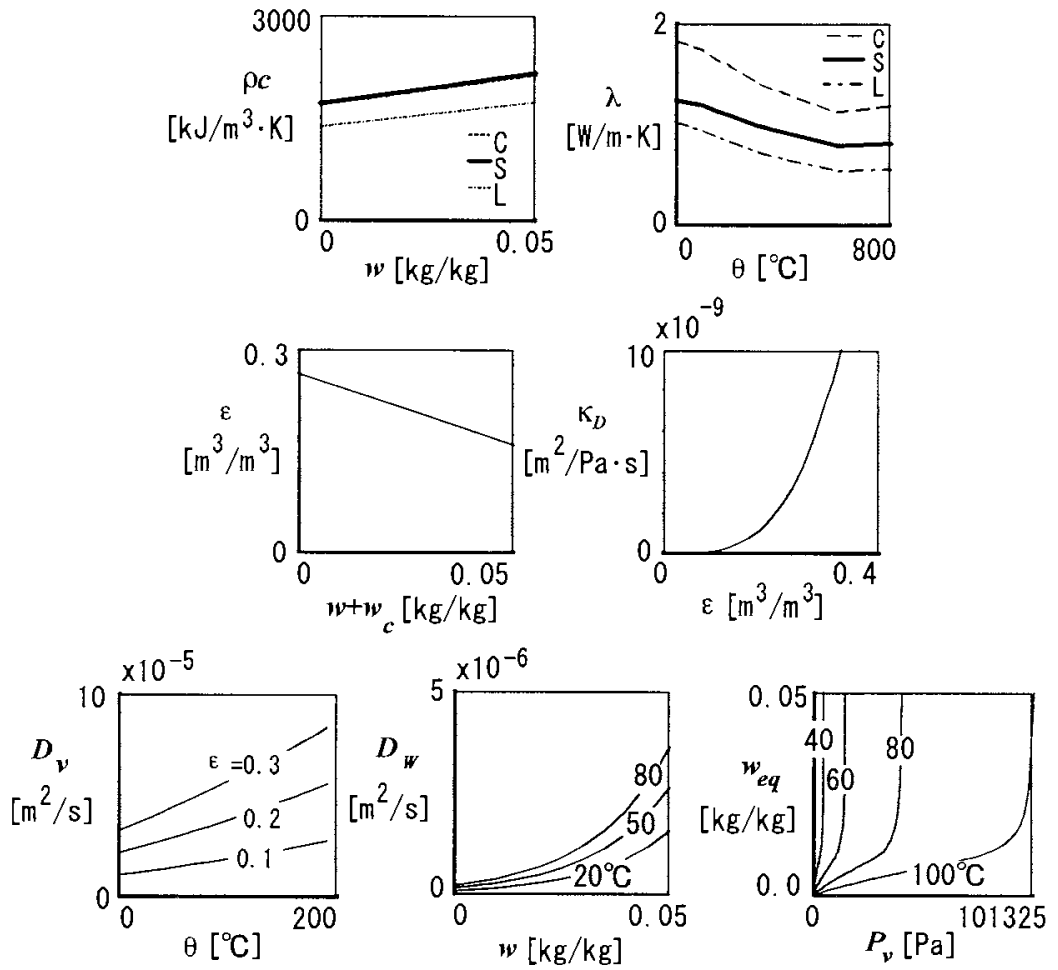

FIGURE 2 Transport parameters of typical sandstone(S), chart(C) and lightweight(L) concrete

\section{VERIFICATION OF THE METHODS10)}

In order to test the accuracy of the method, the published fire test report ${ }^{11}$ ) is simulated by calculation. This was the test of composite slab shown in figure 3 , subjected to JIS standard 
fire for two hours. Initial temperature and water content were $30^{\circ} \mathrm{C}$ and $5.52 \%$ by weight, respectively. According to the JIS procedure, the temperatures of unexposed surface are measured by the thermocouples covered by cedar plate of $15 \mathrm{~mm}$ thick $\left(\mathrm{R}_{1}\right.$ and $\left.\mathrm{R}_{2}\right)$. Its thermal resistance is taken into accounts in the calculations.

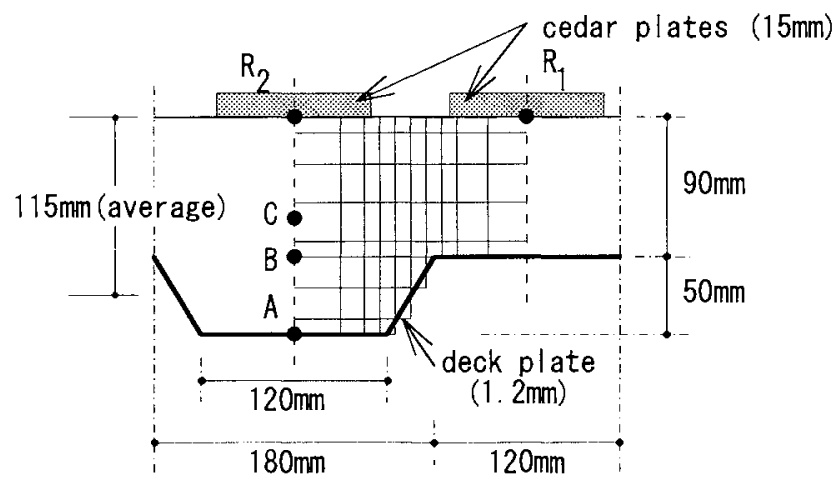

FIGURE 3 Cross sectional shape of composite slab and element division

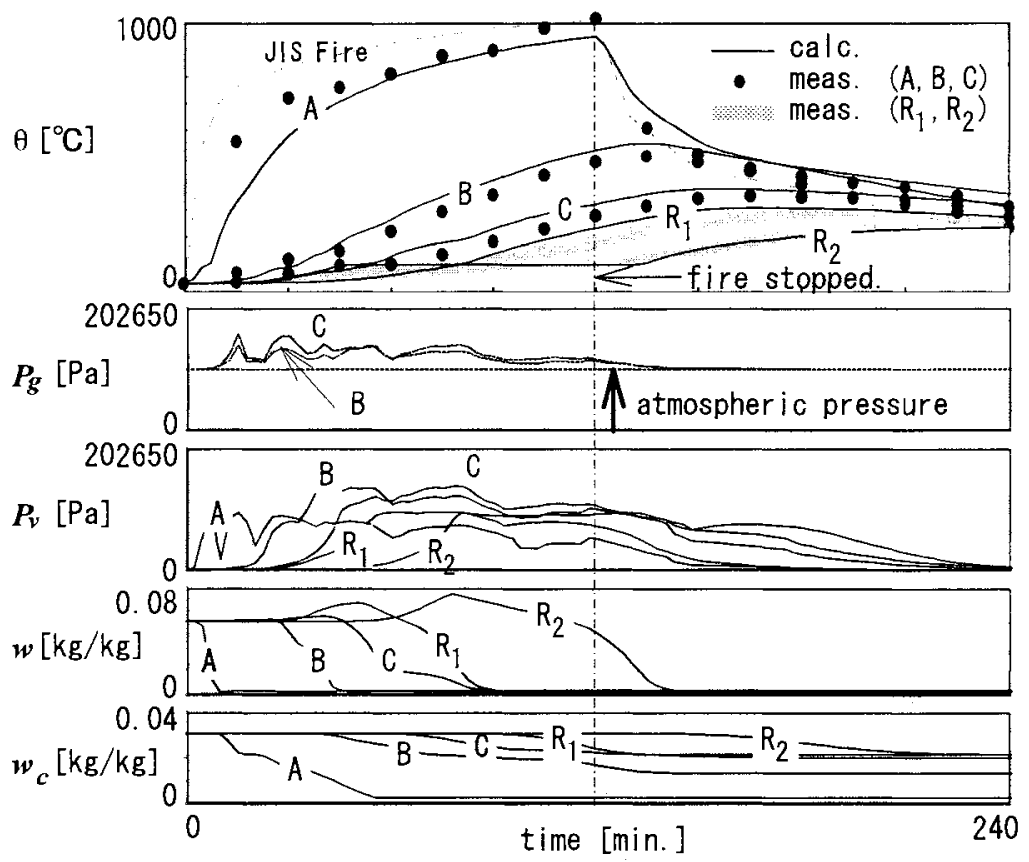

FIGURE 4 Calculated histories at the points $A, B, C, R_{1}$ and $R_{2}$ 
Considering the symmetrical shape, the half part of the cross section is divided into 60 elements as shown in figure 3 . The time increment $\Delta t$ is 6 seconds, which is very large for the calculation of this kind. The computational time was about 800 seconds*

In figure 4 , calculated and measured temperatures at the points $A, B, C, R_{1}$ and $R_{2}$ are shown. At every measuring point, they are in good agreements, including the period of the creeping of temperature. Other variables are also shown in figure 4.

\section{DEPENDENCE OF THERMAL RESPONSES ON CROSS SECTIONAL SHAPES}

In order to find the effects of the rib size on the thermal responses, two kinds of calculations are carried out. The first one is concerned with the cross sectional shapes, and the second one is the effects of concrete properties.

\section{Variations of Fire Resistance Time in case of Sandstone Concrete}

The dependence of the fire resistance time on the cross sectional shapes is calculated for sandstone concrete. The transport parameters are shown as $\mathrm{S}$ in figure 2. Initial temperature is $20^{\circ} \mathrm{C}$. Initial water content is $3 \%$ by weight.

The examined cross sectional shapes are shown in figure 5 . The average thickness, which is equivalent to the concrete volume, is kept constant $\left(H_{\text {ave }}=115 \mathrm{~mm}\right)$ for all the types. The type $\mathrm{S}$ is identical with that of figure 3 . In the series $\mathrm{A}$, the rib height $\left(H_{r}\right)$ of the steel deck is changed from $30 \mathrm{~mm}$ (type L) to $70 \mathrm{~mm}$ (type $\mathrm{H}$ ). The rib width $\left(W_{r}\right)$ is kept to the same, therefore the minimum thickness $\left(H_{m i n}\right)$ is reduced as the rib height is increased.

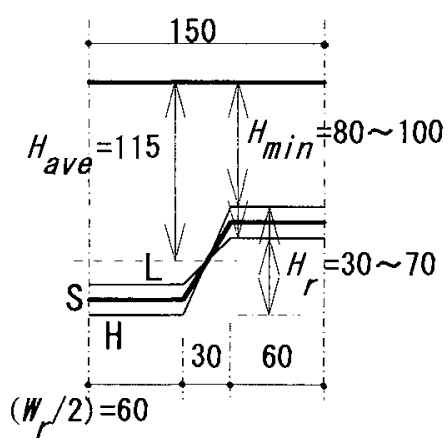

series A: variations of rib height $H_{r}$

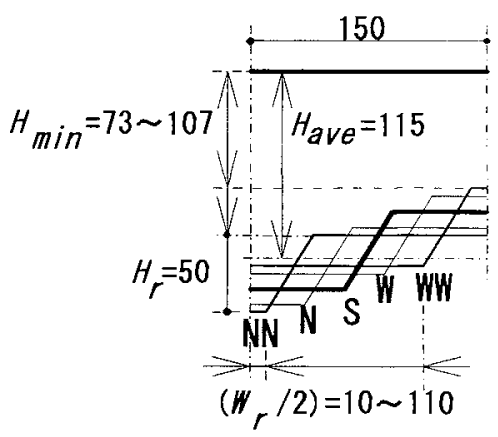

series B: variations of rib width $W_{r}$

FIGURE 5 Variations of the cross sectional shapes (unit in mim)

\footnotetext{
* by Facom VP-2600 (mainframe vector processor at the Data Processing Center of Kyoto University)
} 
In the series $\mathrm{B}$, the rib height is kept constant to $50 \mathrm{~mm}$, and the rib width is varied from $20 \mathrm{~mm}$ (type NN), $70 \mathrm{~mm}$ (type N), 120mm (type S), 170mm (type W) to $220 \mathrm{~mm}$ (type WW) Also in this series, the minimum thickness $\left(H_{\min }\right)$ is reduced as the rib width is increased.

Fire resistance criteria are based on ISO 834 standard. According to it, two limits are defined as to the temperature rise of unexposed surface,

$\left\{\begin{array}{c}t_{\text {ave }} \\ t_{\text {max }}\end{array}\right\}=$ time until the $\left\{\begin{array}{c}\text { average } \\ \text { maximum }\end{array}\right\}$ temperature of unexposed surface rises $\left\{\begin{array}{l}140 \\ 180\end{array}\right\}{ }^{\circ} \mathrm{C}$

The fire resistance time is the shorter one of the two, i.e.,

$t_{f r}=\min \left(t_{\text {core }}, t_{\max }\right)$.

The calculated temperature distributions at the unexposed surface of series $\mathrm{A}$, are shown in figure 6 , as the functions of time. In the cross sectional shapes below, the temperature distributions at the fire resistance time $t_{f r}$ are shown. As the rib height is increased, the fire resistance time is decreased. In case of type $\mathrm{L}$, the isothermal lines are close to horizontal lines, therefore the fire resistance time is determined by the average temperature rise. In case of type $\mathrm{H}$, on the contrary, the isothermal lines are considerably curved, and the temperature rise of the thin parts determines the fire resistance time. In case of type $S, t_{\max }$ and $t_{\text {ave }}$ happen to coincide.

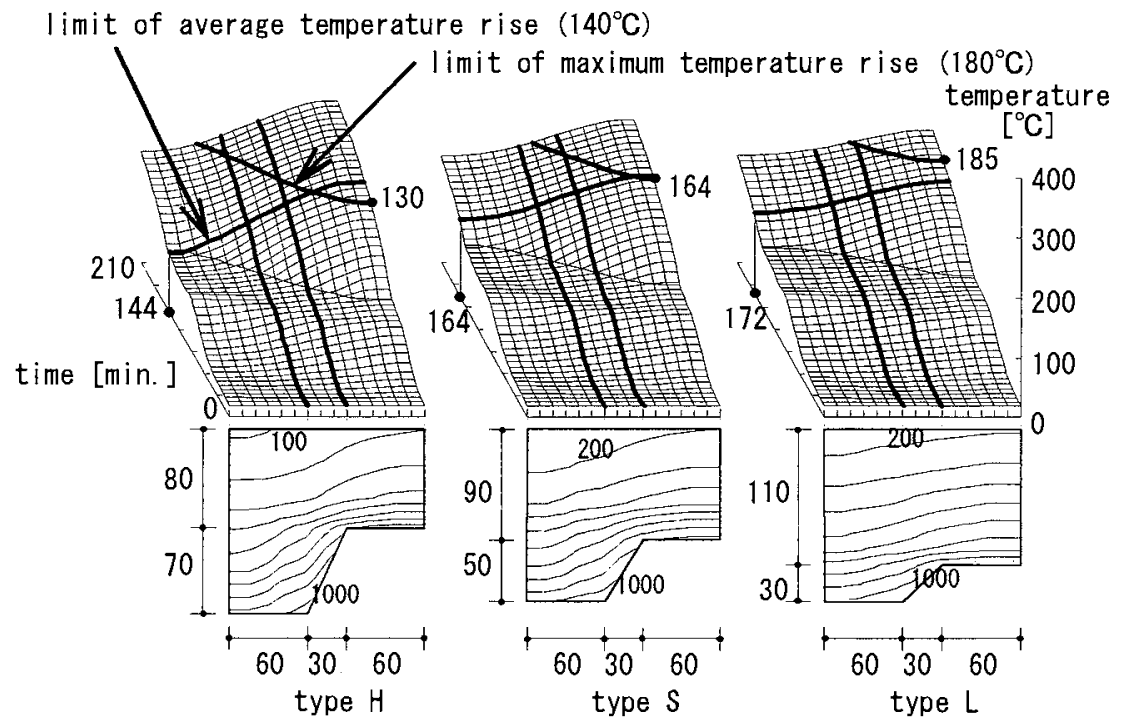

FIGURE 6 Temperature distributions of the unexposed surface (above) and isothermal lines at $t_{j r}$ (below) (Series A) 


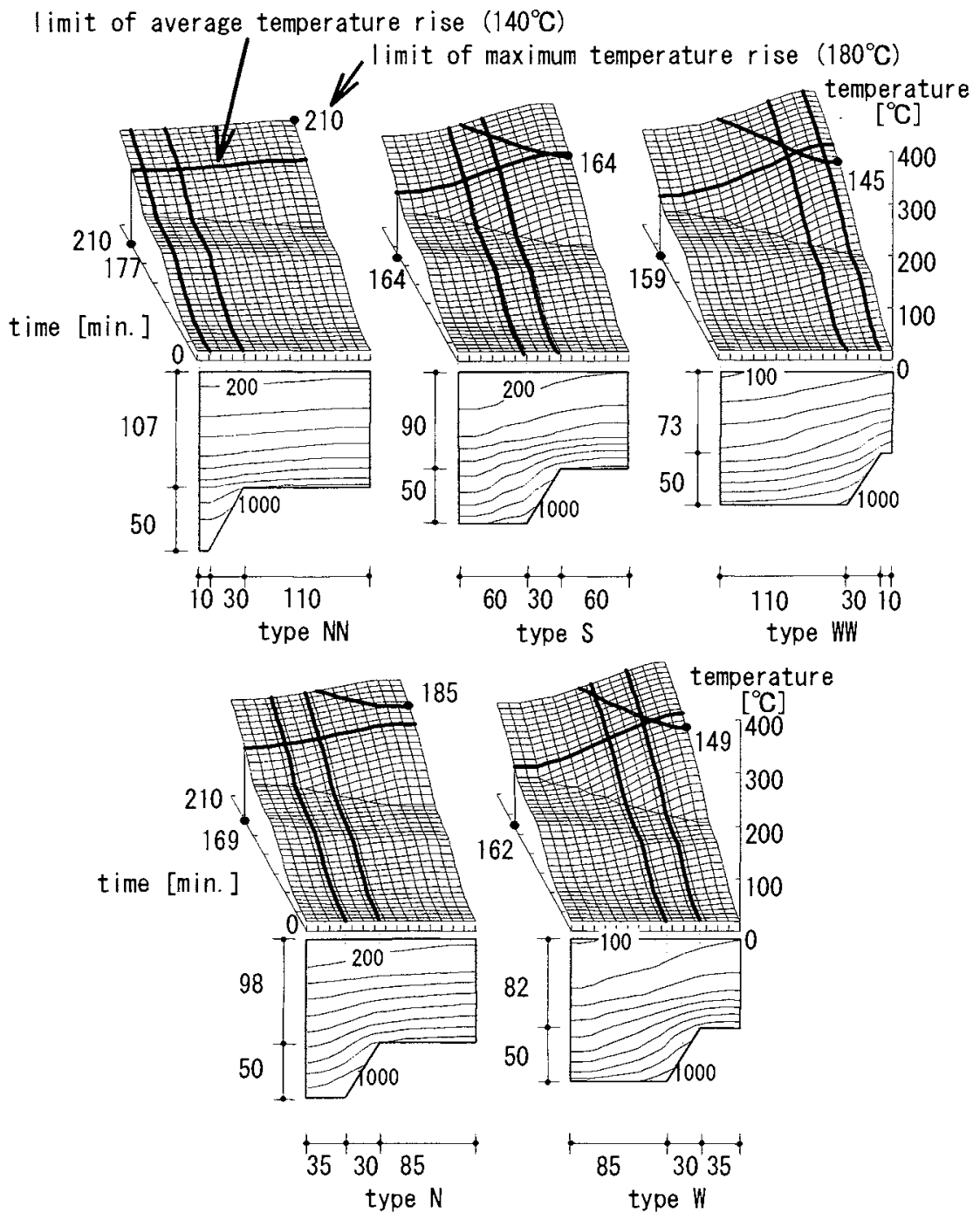

FIGURE 7 Temperature distributions of the unexposed surface (above) and isothermal lines at $t_{\text {,r }}$ (below) (Series B)

The same tendency appears in the results of series B in figure 7. As the rib width is increased, the times determined by the two criteria are decreased. In case of type $\mathrm{NN}$, the effect of the rib is quite small, and the isothermal lines are almost horizontal. Therefore, the thermal response is very close to that of flat slab. As the rib width is increased, the two dimensional effects appear. The most typical one is the type WW. In this case, the temperature rise of thin 
part determines the fire resistance time as also in case of type $\mathrm{L}$ and $\mathrm{W}$.

From the results in figures 6 and 7, it can be concluded as follows. For the uniform thickness slab, the temperature distribution is also uniform, therefore, $t_{\text {max }}$ is greater than $t_{a v e}$. The greater the rib height is, the less the $t_{\text {max }}$ and $t_{\text {ave }}$. The degree of decrease of $t_{\text {max }}$ is greater than that of $t_{\text {cree }}$. In case of type $\mathrm{S}, t_{\text {max }}$ and $t_{\text {ave }}$ happen to coincide. This means there is no redundancy of concrete from the point of unexposed surface temperature rise. We would like to call this feature as 'thermally optimum', but this does not mean mechanically optimum.

The times determined by the two criteria are shown in figures 8 and 9 as the functions of rib width and height. The time determined by the average temperature rise, $t_{\text {ave }}$, is not significantly changed by the cross sectional shapes, whereas the time determined by the maximum temperature rise, $t_{\max }$, is strongly influenced by the rib width and height. It decreases as the rib width and/or height is increased, and the minimum thickness is decreased.

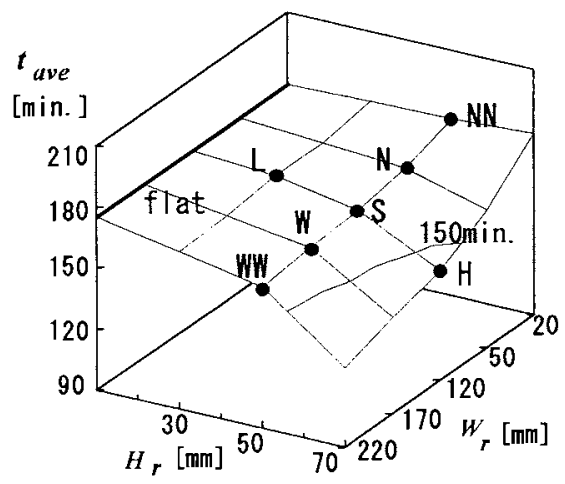

FIGURE 8 Time to rise $140^{\circ} \mathrm{C}$ in average

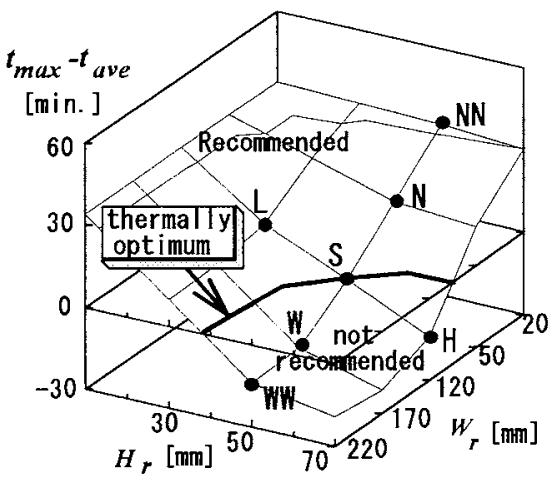

FIGURE 10 Differences of the two times

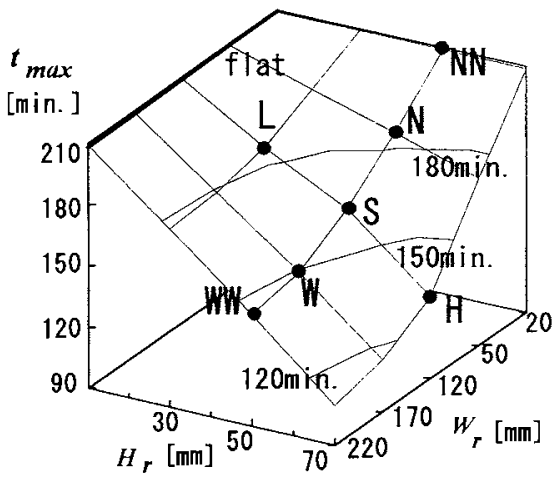

FIGURE 9 Time to rise $180^{\circ} \mathrm{C}$ in maximum

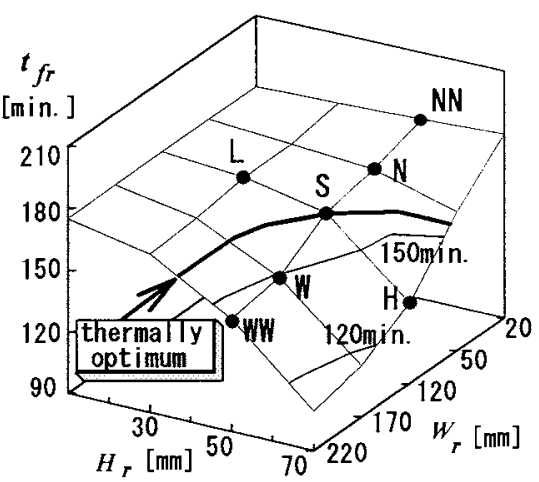

FIGURE 11 Fire resistance time 
The differences between the two times are shown in figure 10. The both times are equal on the contour shown by bold line, thus the cross sectional shapes on this line are thermally optimum. In the zones below the bold line, the fire resistance time is determined by the maximum temperature rise. In this sense, the cross sectional shapes in this area are not recommended. The cross sectional shapes should be selected in the area above the contour line, considering other requirements, such as load bearing capacity and deflections at normal and elevated temperature.

The fire resistance times are shown in Figure 11, as a function of rib height and depth. It is clear that the fire resistance time is considerably reduced if the rib size is greater than the thermally optimum shapes.

\section{Dependence of Temperature Distributions on Concrete Properties}

From the analysis in the foregoing section, it is shown that the type $S$ is thermally optimum for the sandstone concrete, but the thermal properties of concrete differ in a wide range depending on the concrete mix design. Among the aggregates used in practice, chartstone concrete has the largest, and the lightweight concrete has the smallest thermal conductivity. In order to show the dependence on aggregate, calculations are carried out for these two concrete for the type $\mathrm{S}$. The material properties are shown in figure 2 as $\mathrm{C}$ and $\mathrm{L}$.

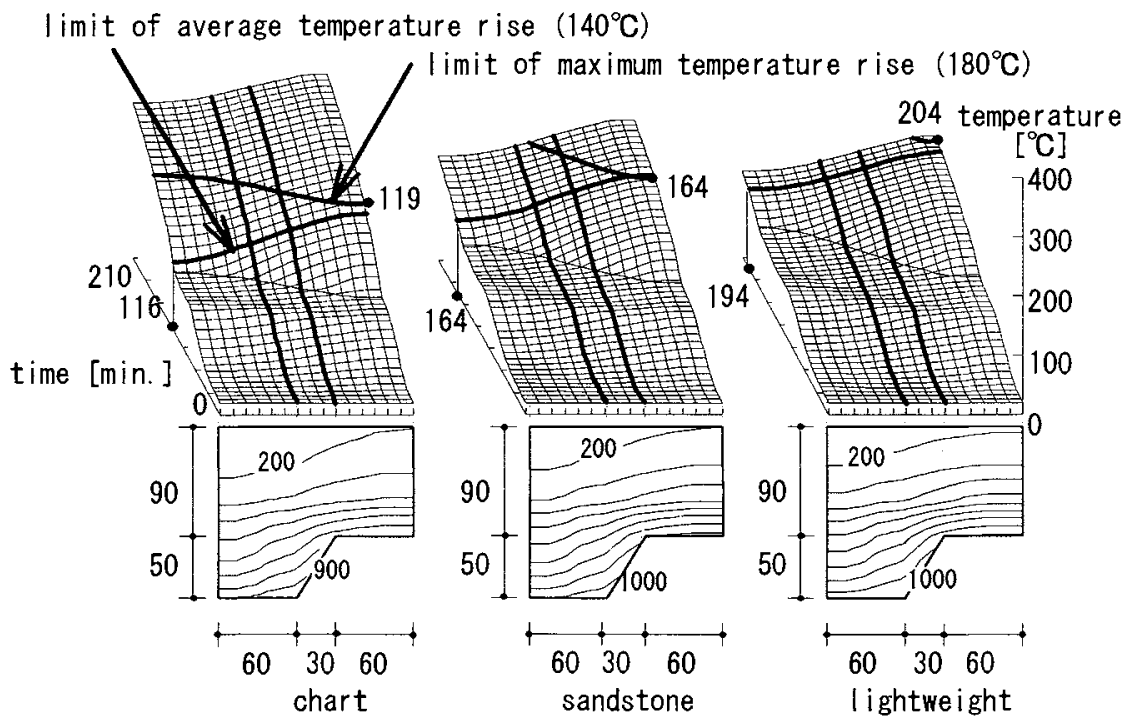

FIGURE 12 Temperature distributions of the unexposed surface (above) and isothermal lines at $t_{f r}$ (below) for type $\mathrm{S}$ cross section with lightweight and chartstone concrete 
The results are shown in figure 12 . In case of chartstone concrete, the both criteria are exceeded much earlier, whereas for lightweight concrete, they are exceeded much later. In both cases, the fire resistance time is determined by average temperature rise. However, the differences between $t_{\text {me }}$ and $t_{\text {nkx }}$ are not so significant, therefore, the type $\mathrm{S}$ is very close to the thermally optimum shape in spite of the differences of aggregates.

\section{Effects of Alterations of Concrete Volume}

The above mentioned thermally optimum cross sectional shapes are valid only for $115 \mathrm{~mm}$ average thickness. If the average thickness is altered, the type $S$ may be no longer thermally optimum. Here, we can extrapolate the results for $115 \mathrm{~mm}$ to other average thickness, and could show a method to find the thermally optimum shapes.

If the thickness is uniformly reduced from that of type $S$, as shown in figure $13(\mathrm{~b})$, the cross sectional shape will be close to that of type $H$. Referring the figure 6 , the fire resistance time will be determined by the maximum temperature rise. Therefore, the rib height and/or width should be decreased as shown in figure 13 (c) or 13(d). Similarly, rib size should be increased when the average height is increased.

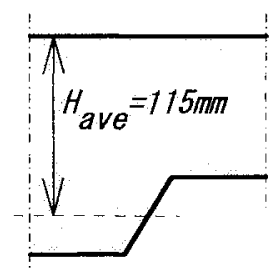

(a)

type $S$

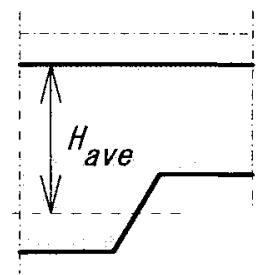

(b)

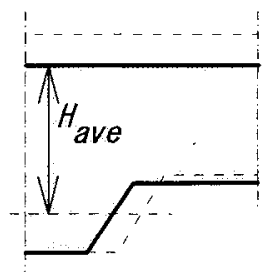

(c) not recommended recommended

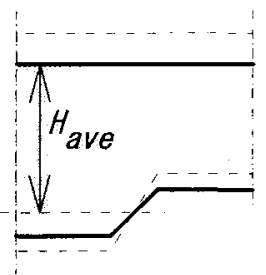

(d)

recommended

FIGURE 13 Reduction of the average height

\section{CONCLUSIONS}

A mathematical model of heat and mass transfer, which is verified by comparisons with existing fire resistance test data, is applied to the composite slabs subjected to ISO fires. By using this model, the relationships between the cross sectional shapes of the composite slab and the fire resistance time are derived as to the sandstone concrete. While the amount of concrete is kept constant, the rib size is changed, and the fire resistance time is determined for each shape. In case of small ribs, the fire resistance time is determined by the average temperature rise. On the contrary, in case of large ribs, the time is determined by the maximum temperature rise. In case of intermediate rib size, both times will coincide, and we call these shapes as 'thermally optimum' in the sense that there is no redundancy of concrete.

Thermally optimum shapes are determined for sandstone concrete of $115 \mathrm{~mm}$ average thickness. They can be considered almost thermally optimum for all the practical mix design 
of concrete. By extrapolating the above results, a qualitative way to find the thermally optimum shapes for other average thickness is considered.

\section{ACKNOWLEDGMENTS}

The authors would like to acknowledge Mr. S. Taji for his valuable instructions about the design of steel decks ${ }^{12)}$.

\section{REFERENCES}

1. Kawagoe,K., Bull. of the Fire Prevention Soc. of Japan, 13:2, pp. 29-35, 1964, (in Japanese)

2. Wakamatsu,T., "Heat Flow Analysis of Building Members during Fire Exposure", Transactions of AIJ, 109 , pp. 73-79, 111, pp.31-36, 1965, (in Japanese)

3. Harmathy, T.,Z., "Simultaneous Moisture and Heat Transfer in Porous Systems with Particular Reference to Drying", Ind. Eng. Chem., 8 , pp.92-103, 1969

4. Huang,C.,L.,D., Siang,H.,H., Best,C.,H., "Heat and Moisture Transfer in Concrete Slabs", Int. J. on Heat and Mass Transfer, 22, pp. 257-266, 1979

5. Sahota,M.,S., Pagni,P.,J., "Heat and Mass Transfer in Porous Media Subjected to Fires", Int. J. on Heat and Mass Transfer, 22, pp. 1069-1081, 1979

6. Harada,K., Terai,T., "Heat and Mass Transfer in an Intensely Heated Mortar Wall", Fire Safety Science, 3, pp. 781-790, Elsevier Applied Science, 1991

7. Terai, T., Harada,K., "A Model of Heat Conduction in Concrete During Fire", The 12th Japan Symposium on Thermophysical Properties, pp. 181-184, 1991, (in Japanese)

8. Harada,K., Terai,T., "Fire Resistance of Concrete Walls", Fire Science and Technology, pp. 215-220, International Academic Publishers, 1992

9. Terai,T., Harada,K., "Fire Behavior of Concrete Members Taking into account Simultaneous Transfer of Heat and Moisture", '93 Asian Fire Seminar, 1993

10. Harada,K., Terai, T., "An Analysis of Heat and Mass Transfer in Composite Slabs during Fire", Architectural Institute of Japan, Kinki Branch, 33, pp.117-120, 1993, (in Japanese)

11. Kouzai Club, Report on the Fire Resistance of Composite Slabs, 1986, (in Japanese)

12. Steel Decks Design and Construction Standards, Ministry of Construction, Japanese Government, (in Japanese) 